\title{
TRADUÇÃO E LITERATURA COMPARADA: MULTIDISCIPLINARIDADE E TRANSCULTURALISMO
}

\section{Alba Olmi*}

\begin{abstract}
RESUMO: Partindo do pressuposto de que a tradução se insere num campo multidisciplinar e transcultural, nossa reflexão procura evidenciar a importância que ela assume não somente como procedimento técnico ou problema fechado, mas como um complexo dinâmico de problemas ligado às obras, à história e à cultura.
\end{abstract}

UNITERMOS: tradução; obra literária; literatura comparada; multidisciplinaridade; transculturalismo.

ABSTRACT: Considering that translation is strictly inserted in a multidisciplinary and transcultural field, this article tries to show its relevance not only as a technical operation, but as a dynamic complex process linked to texts, History and culture.

KEYWORDS: translation; literary work; comparative literature; multidisciplinarity; transculturalism.

$\mathrm{Na}$ efervescência crítico-literária que se experimenta hoje em Literatura Comparada, nos estudos interdisciplinares e multiculturais por ela propostos e propiciados, aparece finalmente um lugar privilegiado que envolve também a tradução e, conseqüentemente, o papel do tradutor, o instrumento mediador entre culturas e provedor de fruição para públicos monoglotas. Os estudos literários comparados, por isso, não estão meramente a serviço das literaturas nacionais: a Literatura Comparada pode contribuir para uma história das formas literárias, para o seu

- Doutora em Literatura Comparada pela UFRGS. Professora do Departamento de Letras da UNISC/RS. 
percurso evolutivo, e situar-se de forma crítica e histórica diante dos fenômenos literários, não se restringindo à busca de imagens, temáticas, influências. Esses aspectos vêm demonstrar não somente os avanços do objeto científico-filosófico denominado interdisciplinaridade, mas também o retorno ao historicismo, entendido aqui como um processo que enfatiza a influência significante da história como critério de valor, pois na visão interdisciplinar não há mais espaço para uma postura a-histórica, seja em relação à literatura, seja em relação a todo e qualquer campo do saber.

É portanto na prática histórica que o discurso humano, real e concreto, é pronunciado e se configura na continuidade do cotidiano. Por essa razão é preciso reafirmar que é na prática que se opera a sintese com a teoria. Nessa perspectiva é também possivel, pois, abordar o fenômeno tradutório e sua avaliação, um processo interativo de ordem epistemológica e antropológica, que envolve língua e literatura, cultura e aspectos filosófi$\cos$, entre outros, porque o traduzir não pode ser definido como um mero procedimento técnico e um problema fechado, mas sim, como um complexo dinâmico de problemas, ligado às obras, à história e à cultura como um todo.

A tradução suscita um interesse sempre maior neste nosso mundo em rápida evolução, e o seu papel principal na comunicação transcultural está cada vez mais em primeiro plano. Com a emergência de culturas e identidades étnicas, antes periféricas ou atê submersas, e a desintegração de hegemonias sociopolíticas consolidadas, a arena geopolítica está passando por profundas mudanças. Em qualquer parte do mundo, essas modificações radicais são acompanhadas por uma difusão geral e por uma diversificação de contatos entre individuos e instituições, e mais forte do que nunca se faz sentir a necessidade de superar toda barreira lingüistica e cultural, para alcançar uma compreensão global. Fundamental é, pois, o papel da tradução: graças a ela podemos trocar informações e conhecimentos em todos os campos do saber, desde o político ao social, do cultural ao econômico, do científico ao tecnológico.

Todos os setores da vida cotidiana são atingidos, de uma forma ou de outra, pela tradução: desde as grandes obras literá- 
rias ao filme e ao documentário; desde os artigos cientîficos aos ensaios acadêmicos; dos livros-texto aos manuais de instruções e de uso. Gerações inteiras cresceram com as traduções: no passado, ouvindo ou lendo histórias infantis; hoje, assistindo aos cartoons pela televisão ou brincando com jogos eletrônicos. Tudo isso nos chega de países próximos ou longínquos, no entanto tudo nos é oferecido de forma tranqüilizadora, numa roupagem conhecida e facilmente reconhecivel, porque "traduzida".

Torna-se cada vez mais evidente que a tradução representa um meio de comunicação muito poderoso. É através dela e do papel mediador dos tradutores que a imagem de um autor e de uma cultura se transferem a outras culturas, e isso salta imediatamente aos olhos na tradução de obras literárias. A idéia que os leitores brasileiros, italianos, franceses, ingleses, espanhóis, americanos terão das obras traduzidas dependerá, em grande parte, de como os originais foram traduzidos na lingua desses leitores.

O poder da tradução, contudo, não se limita a difundir conhecimento e cultura no mundo, ela influencia também a evolução das culturas receptoras. As obras traduzidas podem interagir com as produções autóctones na formação de futuras tendências e desenvolvimentos no âmbito daquela cultura. Na pior das hipóteses, as traduções poderão ser apenas um sucesso em si mesmas, sem contarmos, ainda, com a influência da tradução no percurso das línguas, sobretudo quando os que se apropriam dos textos estrangeiros são escritores. Como oportunamente se manifesta Yves Chevrel, traduzir, editar uma tradução, não significa apenas ocupar-se com uma operação de natureza lingüistica, é também tomar uma decisão que põe em jogo um equilíbrio cultural e social (Chevrel, 1997, p. 355-360).

Considerando a importância e a onipresença da tradução, hoje, não nos surpreende o fato de ela ter recebido tanta atenção de estudiosos empenhados em campos diferentes e que estes tenham contribuido, por sua vez, oferecendo novos insights $\mathrm{e}$ novas perspectivas. $O$ resultado é que hoje a tradução pode ser considerada uma multidisciplina de grande profundidade e amplitude, que busca subsidios em disciplinas as mais diversas: Lingüistica, Literatura, Estudos Culturais, História, Antropologia, Etnografia, Pssicologia, Filosofia, Teologia, entre outras, abra-

TradTerm, 9. 2003, p. 11-26 
çando aspectos diversos: do estritamente teórico ao descritivo e ao aplicado.

Para preservar essa abordagem multidisciplinar, no entanto, é preciso que a tradução seja capaz de fundir e harmonizar a pluralidade de abordagens e de interesses e objetivos num todo orgânico, no qual diversificação e especialização sejam vistas na luz do respeito recíproco, e não numa luz negativa (Ulrich, 1997, p. xii).

A intertextualidade-interdisciplinaridade se configura, pois, como causa e/ou como conseqüência. No processo tradutório, esses dois aspectos, juntamente com o aspecto epistemológico e antropológico, imbricam-se e muitas vezes se confundem, sem ser possivel, com freqüência, estabelecer fronteiras nitidas e priorizar um aspecto em detrimento de outro.

A tradução é, antes de mais nada, uma forma de ler com maior profundidade, para descobrir outras profundezas que uma simples leitura não permite apreender, quando o leitor, tomado pelo prazer imediato do texto, está muitas vezes mais preocupado com ação e trama. De fato, embora o autor queira nos dizer/ comunicar algo sobre o mundo ou a vida, na verdade ele não pretende falar do mundo, mas do ser lingüistico das coisas. Por isso, as abordagens que privilegiam o texto-alvo (TA) parecem anular, ou pelo menos desconsiderar, tanto o texto-fonte (TF) quanto o contexto cultural e literário que lhe deu origem. Isso levaria a uma descontextualização cultural e histórica. Por outro lado, a abordagem que se volta exclusivamente ao TF também deixa de considerar o ambiente em que o texto traduzido passa a ter vida própria. Disso decorre, entre muitos outros, um dos impasses da tradução.

Para Walter Benjamin (1994), a preocupação em saber como a obra será recebida nunca se revela fecunda. Toda referência a um público determinado ou aos seus expoentes culturais desviaria a obra de arte. Além disso, também o conceito de destinatário "ideal”, na visão de Benjamin, é nocivo a qualquer indagação estética, já que esta tem por compromisso a pressuposição da existência e da natureza do homem em geral. Na avaliação de Wesling e Lefevere, o conceito de autonomia da obra de arte, em Benjamin, deve-se provavelmente à situação de absoluta solidão em que o intelectual vivia, mas também "à necessidade de 
salvaguardar a pureza da arte num mundo cada vez mais mercantilista" (1970, p. 126), e sua escritura, a meio-caminho entre o literário e o filosófico, lhe ofereceu a salvação que veio do misticismo judeu, do marxismo e da própria arte.

Nessa visão de arte, teriamos, como conseqüência, também a autonomia da tradução, que não estaria endereçada àqueles leitores que não compreendem o original, por ser ela uma forma, e essa forma nada mais é do que the speaking physiognomy of everything which, undistorted by any disturbing accidents, bears true witness to its hidden nature (Schlegel apud Wesling e Lefevere, 1970, p. 126). ${ }^{1}$

Há, contudo, outras posições teóricas que consideram de forma diferente a comunicação que se estabelece entre texto e leitor. Na opinião de Coulthard (1992), ao produzir um texto que poderá ser lido por milhares de leitores, o autor não o cria para nenhum desses leitores reais. Ao contrário, ele constrói um leitor ideal em sua mente, atribuindo-lhe o conhecimento de fatos, a memória de certas experiências, suas preferências ou seus preconceitos e um determinado nivel de competência lingüística.

A partir desse momento, todos os recursos expressivos utilizados pelo autor serão selecionados em virtude desse leitor ideal, de forma que todo texto, ao ser concluído, definirá seu leitor ideal. Por essa razão Coulthard define o tradutor como alguém que, partindo de um texto inacessivel a um determinado grupo de virtuais leitores, tenta produzir um novo texto que seja acessivel a esses leitores. Vista por esse ângulo, a tradução pode dar-se não só de uma língua para outra, mas também de forma intralingüistica. Isso pode ocorrer com textos arcaicos, adaptações de clássicos (para adultos e crianças), entre outras re-escrituras, que não podemos tomar aqui como traduções, no sentido restrito do termo.

Quanto ao texto temporalmente deslocado, fora do passado de sua língua e de sua literatura, para Steiner (1995, p. 1-48)

1 "A fisionomia falante de tudo aquilo que, sem distorções de qualquer natureza, dá o verdadeiro testemunho de sua natureza oculta." [Todas as traduções que constam deste trabalho são de minha autoria.] 
também representa um ato plural de interpretação, já que a língua está em constante mudança, uma mudança que não é apenas da ordem quantitativa de eventos lingüisticos, mas de ordem qualitativa.

Se elas ocorrem em seqüência temporal, duas frases podem não ser perfeitamente idênticas, porque, embora homólogas, os eventos da língua interagem. Civilizações e épocas diferentes não produzem necessariamente a mesma fala. Além disso, enquanto algumas culturas valorizam a concisão, outras preferem o prolixo e o ornamento semântico.

Outro aspecto salientado por Steiner é o que se refere à diferença entre o que nós dizemos para nós mesmos e o que comunicamos a outros: não foi e não será o mesmo conteúdoforma em todas as culturas ou nos seus estágios de desenvolvimento lingüístico. Cada ato lingüístico possui, portanto, um determinante temporal, toda forma semântica possui a sua época, o seu tempo.

Ler em profundidade é, pois, restaurar, recuperar tudo aquilo que é possível do valor e da intenção em que "o ato de fala" realmente ocorreu. Esses aspectos parecem ainda mais relevantes quando transferidos ao ato tradutório em que a interpretação, que confere vida à língua, vai além do momento e do lugar da elocução imediata ou de sua reescritura.

$\mathrm{O}$ ato de traduzir é visto por Steiner como uma atividade envolvida na apropriação do TF, de modo que a captura do texto pelo tradutor deve ser compensada por um gesto de restituição. Uma orientação que se coaduna com a de Benjamin (Op. cit.) que vê no tradutor a figura do messias, do redentor, daquele que "restitui" a língua pura.

Infere-se que a tradução pode ser tão ou mais importante que a própria crítica, a qual, conforme Benjamin, é também um elemento de sobrevida da obra literária, embora um elemento bem menor, donde ressalta a importância e a responsabilidade do tradutor.

Num enfoque crítico e histórico, Bassnett discute a importante relação entre literatura comparada e estudos da tradução, que por um longo periodo foram relegados a um patamar inferior, como se fossem uma atividade menor que exigiria pouco 
talento e pouca criatividade. A autora enfatiza a evolução atual que permitiu enfoques mais ousados:

The challenge to the original like the challenge to the canon or to the notion of correct, single reading is clearly part of a wide-ranging post-modernist strategy. Instead of reading for 'truth', we now read as decoders. (Bassnett, 1993, p. 141$)^{2}$

Bassnett traça um panorama em que se distinguem três estágios no desenvolvimento dos estudos de tradução. A primeira fase, dos anos 70, influenciada pela teoria dos polissistemas, envolve uma quantidade de desafios para o discurso que se estabelece sobre tradução, e cruciais, nessa fase, são os acirrados debates sobre a teoria da equivalência.

O conceito tradicional é que a tradução entre linguas é possivel, devido à existência prévia de uma equivalência nocional entre os sistemas lingüisticos, conceito que contraria a hipótese Whorf-Sapir, segundo a qual nenhuma língua é suficientemente semelhante a outra, para poder representar a mesma realidade social. Para Bassnett, o problema da teoria da equivalência é que ela nega a existência de relações hierárquicas entre textofonte, texto-alvo e suas respectivas culturas, presumindo que a tradução ocorreria num eixo vertical, entre sistemas situados de forma idêntica. A teoria dos polissistemas, ao contrário, sustenta que os sistemas literários nunca estão situados de forma idêntica, e que os conceitos de superioridade/inferioridade de um texto ou de um sistema literário estão sempre em jogo.

A segunda fase, lembra a autora, centrou-se na criação de padrões para a atividade tradutória em determinados momentos no tempo, e a ênfase dessa abordagem continuou orientada para a lingua-alvo. O que renovaria de forma significativa o enfoque anterior, enraizado no estruturalismo, representando um passo importante a caminho dos estudos de tradução do pós-

2 "O desafio ao original, bem como ao cânone ou ao conceito de leitura única e correta, é parte evidente de uma estratégia pós-moderna de amplo alcance. Ao invés de ler pela 'verdade', agora nós lemos como decodificadores." 
estruturalismo, seria o trabalho empreendido sobre os tradutores do Renascimento a respeito da linguagem figurada.

Em seu ensaio sobre os tradutores da época renascentista, que trabalharam com o inglês, francês e holandês, Theo Hermans (1985), citado por Bassnett, categoriza o uso das metáforas, descrevendo assim claros modelos de pensamento que revelam as estratégias tradutórias subjacentes, bem como o direito de a cultura-alvo possui-las. O trabalho de $T$. Hermans revela também padrões de pensamento que esclarecem o papel e o status da tradução daquele tempo. O conceito do tradutor como escravo do $\mathrm{TF}$ prevaleceria até o século $\mathrm{XX}$, deixando transparecer claramente a idéia de dominância exercida pelo original sobre a tradução.

O enfoque da linguagem metafórica em tradução se constitui num aspecto relevante da terceira fase. Diversos trabalhos nesse sentido, no início dos anos 1980, apesar de apresentarem-se como não-normativos, ainda preservam fundamentos estruturalistas. Contudo, pela metade da década, ocorre uma discreta diversificação de abordagens nas quais o conceito de pluralidade substitui as normas dogmáticas de fidelidade ao original, ocasião em que o TF é desafiado por muitas novas perspectivas.

$\mathrm{Na}$ linha teórico-critica de Lefevere (1992), amplamente favorável aos processos manipulativos do texto, encontramos posicionamentos de ordem pedagógica, sociocultural e político-ideológica. Argumenta Lefevere que os escritores pertencem a uma determinada cultura, a um determinado tempo, herdando, dessa forma, suas tradições literárias, seus padrões, seu universo discursivo. Contudo isso não significa que eles devam ser escravos dessa cultura: os escritores tanto podem opor-se aos parâmetros estabelecidos, como também ultrapassá-los.

Esse aspecto não inclui somente o nivel lingüístico, mas também o universo discursivo, o poético e o ideológico. Por essas razões, muitas vezes o tradutor precisa desenvolver estratégias capazes de lidar com esses problemas, podendo hierarquizar os niveis, de acordo com as dificuldades de cada tradução, em ordem decrescente: nivel ideológico, poético, universo discursivo, lingua.

TradTerm, 9, 2003, p. 11-26 
Essa hierarquização possui, entre outros, o mérito de neutralizar os preconceitos correntes a respeito da tradução, segundo os quais traduzir é apenas substituir palavras e frases por outras que façam sentido. Por outro lado, certas táticas tradutórias podem chocar-se com o nivel lingüístico, ideológico ou poético. O autor considera que aspectos de estilo ou alusões culturais não podem ser omitidos e, se importantes, devem ser realçados.

O produto da tradução, as estratégias que subjazem ao produto, os objetivos da tradução e o papel exercido pela obra traduzida em determinada literatura e cultura, afirma o autor, representam elementos capazes de abrir caminho para o incremento dos estudos de tradução no ambiente acadêmico, já que o estudo do produto final, o TA, está em estreita consonância com a Teoria da Literatura e com a Historiografia. Lefevere considera impossível analisar uma tradução sem um bom conhecimento do processo tradutório, e sem situar o estudo da tradução em seu amplo contexto cultural, juntamente com as questões de poder e de manipulação textual que tais análises podem levantar.

O problema da tradução é tão antigo quanto a diversidade das línguas, e sua origem se perde na noite dos tempos. Aceitando a lenda da Torre de Babel, poder-se-ia reconduzi-lo ao momento em que se afirmou a humana presunção, punida com o estranhamento recíproco dos seres humanos. E como se ainda estivesse relacionado a essa punição, o problema da tradução continua a ser proposto e reproposto, continuando a ser discutido, porque ainda não resolvido: Mentre l'altezza della torre di Babele è già stata superata innumerevoli volte, il problema della traduzione, in ogni epoca, sembra restare sempre ugualmente lontano dalla sua soluzione (Apel, 1997, p. 23). ${ }^{3}$

Entre a primitiva fidelidade literal das mais antigas formas de tradução, entre o ciceroneano non verbum pro verbo reddere, entre a liberdade francesa e a fidelidade alemã, entre a covert e overt translation (tradução encoberta e evidente), segundo nomenclatura de House (1997), a teoria da tradução literária não consegue superar seu impasse: partir do TF ou do TA, levar

3 "Enquanto a altura da Torre de Babel já foi ultrapassada inúmeras vezes, o problema da tradução, em todas as épocas, parece permanecer sempre longe de uma solução." 
o leitor em direção ao autor, ou fazer o autor caminhar em direção ao leitor? Segundo o que propõe Schleiermacher, haveria, de fato, apenas duas vias possiveis:

Mas então, que caminhos pode tomar o verdadeiro tradutor que quer aproximar realmente essas duas pessoas tão separadas: o escritor de origem e seu leitor e facilitar a este, sem obrigá-lo a sair do circulo da sua lingua materna, a compreensão e o deleite mais exatos e completos do primeiro? A meu ver, há apenas dois. Ou o tradutor deixa o escritor em paz o mais possivel e conduz o leitor até o escritor, ou ele deixa o leitor em paz o mais possivel e conduz o escritor até o leitor. (Schleiermacher, 1838, p. 218)

Nas últimas décadas, felizmente, o campo da tradução veio avançando e gerando idéias e teorias cada vez mais aprofundadas, de modo a ampliar os horizontes e reconsiderar conceitos tradicionais, que favoreceram o surgimento de novos paradigmas por meio da identificação de fatores sociais, culturais e históricos no processo tradutório que, pelo seu caráter de comunicação intercultural e social, está sujeito a pressões ideológicas e de poder. É sabido que fatores extra-lingüisticos condicionam a tradução em dado momento histórico.

A recusa de uma abordagem prescritivo-normativa em favor de uma metodologia critica de caráter funcional e descritivo constitui o mérito inovador que caracteriza a abordagem histórico-sociológica de Lefevere (1998). Na abordagem por ele proposta, não há lugar para indicações ou normas aptas a realizar a tradução ideal. O autor privilegia a análise do texto traduzido como meio de detectar as normas ou as convenções que influenciaram o processo. De acordo com a abordagem descritiva, a análise de uma tradução acontece preliminarmente com base em critérios que pertencem à cultura-alvo, aquela que regula sua acolhida. Somente num segundo momento é que se realiza o confronto com o original. Dessa forma, a análise do texto traduzido se processaria de forma acrítica, recusando qualquer abstração apriorística sobre o grau de equivalência dos dois textos em jogo ou sobre os limites da traduzibilidade.

$\mathrm{Na}$ ótica metodológica descritiva, o conceito de equivalência passa portanto a relativizar-se pela sua variabilidade de um

TradTerm, 9, 2003, p. 11-26 
texto a outro, ocorrendo assim um nítido desvio de interesse que se orienta para o TA. Ao mesmo tempo, reforça Lefevere, ampliase o conceito de tradução, porque cada operação tradutória prevê a manipulação do $\mathrm{TF}$, que se origina na interpretação subjetiva do tradutor e na mudança de côdigo lingüístico, mas também na influência de fatores socioculturais e históricos, e na recepção do texto traduzido na cultura de chegada. ${ }^{4}$

Para Lefevere, que atuou sobretudo na tradução literária, o processo tradutório é essencialmente uma re-escritura, englobando-se nesse termo todos os tipos de manipulação textual tanto as traduções entre sistemas culturais diferentes, como também a re-interpretação de um texto dentro de uma mesma cultura. Nesse conjunto, o autor inclui adaptações cinematográficas e teatrais, literatura infantil, edições reduzidas, antologias, critica e historiografia literária.

Fica evidente, portanto, que essa abordagem coloca lado a lado re-escritura e tradução stricto sensu, em âmbito intra e intercultural. Lefevere considera que dessa forma grande parte da literatura canônica é divulgada pelas diversas modalidades de re-escritura e dos processos de aculturação peculiares de cada sociedade, como meio de favorecer uma maior compreensão.

A tese defendida por Lefevere é a de que uma obra literária só pode ter acolhida na sociedade receptora se for traduzida ou re-escrita de acordo com os valores dominantes daquela sociedade. Infere-se, desse posicionamento, que quanto mais semelhantes forem as duas culturas em jogo, menor deverá ser a manipulação e vice-versa. ${ }^{5}$

Desse processo de manipulação textual surge uma obra posta a serviço do poder que, dependendo das circunstâncias, poderá repercutir positiva ou negativamente. Num viés positivo, a re-escritura, e particularmente a tradução stricto sensu, pode contribuir para a evolução de um sistema literário e social, favore-

4 Sobre estudos descritivos, Descriptive Translation Studies (DTS), ver TOURY, Gideon: "A rationale for descriptive translation". Dispositio, vol. 7, University of Michigan, p. 23-49, 1983. Ver também TOURY, Gideon. "Translation, literary translation and pseudotranslation. Comparation criticism", 1984. p. 73-85.

TradTerm, 9, 2003, p. 11-26 
cendo a migração de novos gêneros, estilos e temáticas para a literatura de chegada.

No viés negativo, a re-escritura (no sentido de manipulação) poderá reprimir a inovação e construir imagens falsas e ideologicamente marcadas, colocando o processo tradutório no seu contexto histórico, enfatizando assim o papel central que a re-escritura, em suas diversas formas, exerce na evolução histórica de uma literatura. As premissas desses processos Lefevere as busca na concepção sistêmica dos formalistas russos, concepção retomada, ampliada e elaborada pela Teoria do Polissistema, por Itamar Even-Zohar (1973) e Gideon Toury (1981). ${ }^{6}$

Dessa forma, Lefevere acredita que a modalidade tradutória por ele defendida possa auxiliar a transferir os estudos de tradução da periferia da Literatura Comparada e da Teoria da Literatura para uma posição mais centralizada. Na opinião do autor, uma visão capaz de reconhecer a construção de obras consagradas saberá reconhecer também o papel das re-escritu-

5 Sobre a tradução "comunicativa" - uma modalidade tradutória - há opiniōes contrárias, que a consideram uma re-escritura, uma vulgarização que pode ser inclusive intralingüistica e que constitui apenas uma simplificação do original. Ver MASCIALINO, R. Studio sulla traduzione letterária. Udine, La Nuova base, 1996. p. 65-70.

6 Com base nessa teoria, o sistema literário, que é parte do conglomerado de sistemas de uma cultura, é por sua vez uma estrutura complexa. Trata-se de um polissistema em estado evolutivo e transformativo continuo. A teoria do polissistema resultou ser de grande utilidade para identificar o lugar que a traduçāo ocupa dentro dos sistemas literários e culturais, já que ela realiza uma função primária na evolução histórica das várias literaturas, seja em introduzindo inovações literárias na cultura de chegada, seja ao contribuir com a consolidação do cânone vigente, embora de forma menos contundente. Uma vez que os estudos diacrônicos comprovaram que a importāncia de um texto não é imutável, mas varia em função das convenções e dos gostos do contexto histórico-cultural, a teoria polissistêmica conduziu a uma reavaliação do impacto de fatores extralingüisticos no desenvolvimento dos patrimônios culturais e literários de todo o polissistema, permitindo que o fenômeno da tradução se colocasse numa perspectiva muito mais ampla do que a essencialmente lingüistica. 
ras que não neguem ou desvirtuem o valor intrínseco das próprias obras.

As obras não re-escritas, conclui Lefevere, de uma forma ou de outra tendem a ser esquecidas ou a desaparecer, e o papel do critico deve deixar de ser o do mediador - "essa figura sacerdotal" - de modo que o cânone deixe de ser aceito como autoevidente ou interpretado em sua "infinita perfeição".

$\mathrm{Na}$ perspectiva preconizada pelo autor, o tradutor será o historiador, o sociólogo, o técnico. O cânone poderá ser enfrentado, desafiado, modificado e visto em sua evolução histórica. Tudo isso se torna possível via tradução, a qual possibilita a análise da recepção de obras estrangeiras dentro de uma literatura nacional e, conseqüentemente, o seu confronto e a sua avaliação.

A linha defendida por Lefevere traz à tona, obrigatoriamente, o conceito de semelhança, literalidade, fidelidade, ética da tradução. No Brasil, José Paulo Paes enfatiza, para a tradução, o relevante conceito de "paramorfia", argumentando que essa se constitui numa similitude formal e semântica possibilitada pelas especificidades dos dois idiomas em causa, capaz de preservar as peculiaridades estilisticas e gramaticais que assinam o texto literário. O autor acrescenta que a tradução louvável é aquela que, sem desvirtuar as normas da LA, deixa filtrar aquelas caracteristicas diferenciadoras, de estranhamento, que, embora limitadas, permitem inferir as diferenças de visão de mundo entre LF e LA, e sustenta ainda:

A idéia corrente de que boa é a tradução que dá ao leitor a mesma impressão de um texto originariamente escrito em sua lingua pátria, constitui a maior das falácias. Pelo menos desde Humboldt, sabe-se que cada idioma consubstancia uma experiência diferencial do mundo; é um recorte da realidade diverso, na sua especificidade, dos demais recortes operados pelos outros idiomas. Isto não quer dizer que sejam acessiveis apenas aos seus respectivos falantes tais visōes de mundo diferentemente expressas por cada idioma em nivel tanto lexical como morfológico e sintático. A tradução alcança trazê-la em parte até o entendimento de falantes de outro idioma por via de uma operação antes de caráter transpositivo que redutor. Tendo-se bem 
presente o que possa haver de diferencial na língua de partida em relação à língua de chegada, busca-se exprimi-lo através dos recursos próprios desta. Nessa operação transpositiva, visa-se portanto menos a uma impossivel isomorfia - perfeita simetria no espirito e na letra - do que a uma possivel paramorfia - [grifos do autor] a similitude de forma e significado que as idiossincrasias dos dois idiomas franqueados pela ponte tradutória permita. (Paes, 1990, p. 93)

Efeitos semelhantes, para Paes, não significam efeitos iguais, ou isomórficos. É preciso conceber a tradução como técnica de equivalência ou aproximação, ou seja, é preciso "modalizar pragmaticamente a antitese traduzivel/intraduzivel" (Paes, 1990, p. 115). Somente assim a eficácia tradutória acaba de vez com a submissão idólatra ao original, concedendo à obra traduzida o seu estatuto de equivalência com o original, conclui o autor. Dessa forma, a obra traduzida assume status de equivalência com o original, que é o estado possivel noutro idioma. $\mathrm{O}$ adjetivo "possivel" passa a significar, para Paes, a exclusão do conceito de tradução definitiva, já que a tradução não está livre da ação histórica, podendo ser refeita de forma mais apurada ou de forma mais condizente com o espirito da época.

A posição de Milliet (1984) parece bem próxima da visão de Paes. Para Milliet, as qualidades exigidas do tradutor são inteligência, modéstia, penetração crítica e espirito inventivo. É esse espírito criador que confere à tradução (e ao tradutor, evidentemente) o direito de situar-se num plano semelhante ou de igualdade ao do autor/obra original.

Partindo desses pressupostos, a obra literária, original ou traduzida, "não pode mais ser vista como algo acabado a deslocar-se intocável no tempo e no espaço, mas como um objeto mutável por efeito das leituras que a transformam" (Carvalhal, 1998, p. 68). Na perspectiva da Literatura Comparada, a ressonância que uma tradução provoca "diz muito sobre a obra, mas também sobre o sistema literário que a acolhe" (Carvalhal, 1998, p. 71), proporcionando a possibilidade de estudos de recepção comparada capazes de realizar o confronto entre dois sistemas 
literários, ampliando assim as possiveis leituras da obra em questão.

Define-se, dessa forma, a estreita relação que se estabelece entre tradução e literatura comparada, cuja tarefa é a de "estudar a capacidade de desenvolvimento da literatura receptora para realizar relações interliterárias pela recepção" (Nitrini, 1997, p. 96), desenvolvimento esse tornado possivel pela tradução das obras, o que pode promover a autonomia e a individualidade das literaturas nacionais.

\section{Referências bibliográficas}

APEL, F. (1997) L'anelito all'integrazione linguistica. In: .Il movimento del linguaggio. Trad. Riccarda Novello. Milano, Marcos y Marcos. p. 187-270. Trad. de: Sprachbewegung, 1982.

BASSNETT, S. (1993) From comparative literature to translation studies. In: . Comparative literature: a critical introduction. Oxford, Blacknell. p.138-161.

CARVALHAL, T. F. (1998) Literatura comparada. 3. ed. São Paulo, Ática. BENJAMIN, W. (1994) A tarefa do tradutor. Trad. de vários. 2. ed. rev. e ampl. dos Cadernos de Mestrado/Literatura. Rio de Janeiro, UERJ. Trad. de: Die Aufgabe des Übersetzers, 1923.

CHEVREL, Y. (1997) Les traductions: un patrimoine littéraire? Revue d'Histoire Littéraire de la France. n. 3, Paris, p. 355-360, Mai-Juin.

COULTHARD, M. (1992) Linguistic constraints on translation. Tha do Desterro, v. 28, Florianópolis, Editora da UFSC, p. 9-23, II sem.

EVEN-ZOHAR, I. (1973) A funçāo do polissistema literário na história da literatura. Trad. Ubiratan Paiva de Oliveira. (Mímeo)

HOUSE, J. (1997) Translation quality assessment : a model revisited. Tübingen, Gunter Narr.

LEFEVERE, A. (1992) Translating literature: practice and theory in a comparative literature context.. New York, MLAA.

. (1998) Il sistema e il patronato. In: . Traduzione e riscrittura: la manipolazione della fama letteraria. Trad. Silvia Campanini. Torino, UTET. p. 11-25. Tradução de: Translation, rewriting and the manipulation of literary fame, 1992.

MILLIET, S. (1984) Diário crítico. In: SIMON, I. M. (org.). Território da traduçāo. Campinas, Universidade Estadual de Campinas - Instituto de Estudos da Linguagem. p. 187-200. 
NITRINI, S. (1997) Literatura comparada: história, teoria e crítica. São Paulo, EDUSP.

PAES, J. P. (1990) Tradução: a ponte necessária. São Paulo, Ática.

SCHLEIERMACHER, F. D. E. (1838) Uber die Verschiedenen Methoden des Übersetzen. In: . Sämtliche Werke, Dritte Abteinlung: Zur Philosophie Zweiter Band. Berlin, Reimer. p. 218.

STEINER, G. (1995) Dopo Babele: aspetti del linguaggio e della traduzione. 2. ed. riveduta e attual. Trad. Ruggero Bianchi. Integrazioni e varianti tradotte da Claude Bëguin. Firenze, Garzanti.

TOURY, G. (1981) Translated literature: system, norm, performance. Toward a TT Oriented Approach to literary translation. Poetics Today. v. 2, n. 4, Tel Aviv, Porter Institute for Poetics and Semiotics, p. 9-27. Summer/Autumn.

ULRYCH, M. (a cura di). (1997) Premessa. In: Tradurre: un approccio multidisciplinare. Torino, UTET.

WESLING, D.; LEFEVERE, A. (1970) The mistery of translation. Babel, v.16, Paris, FIT - Fédération Internationale des Traducteurs. p. 124134. 